\title{
Competição entre híbridos de milho com plantas daninhas
}

\author{
Submetido - 03 out. $2020 \quad$ Aprovado - 15 out. $2020 \quad$ Publicado - 18 nov. 2020
}

Engenheiro Agrônomo, Doutor em Fitotecnia, professor do curso de Agronomia e do Programa de Pós-Graduação em Ciência e Tecnologia Ambiental da Universidade Federal da Fronteira Sul, Campus Erechim; e-mail: leandro.galone@gmail.com.

Ricardo Luis Gabiatti

Biólogo, Mestrando do Programa de Pós-Graduação em Ciência e Tecnologia Ambiental da Universidade Federal da Fronteira Sul, Campus Erechim; e-mail: ricardo.gabiatti@edu.sesisc.org.br.

Luciane Renata Agazzi (iD

Discente de Agronomia da Universidade Federal da Fronteira Sul, Campus Erechim, e-mail: luci_agazzi@hotmail.com.

Sabrina Natalia Weirich (iD

Discente de Agronomia da Universidade Federal da Fronteira Sul, Campus Erechim; e-mail: weirichsabrina@hotmail.com.

André Luiz Radünz

Engenheiro Agrônomo, Doutor em Agronomia, professor de Fitotecnia da Universidade Federal da Fronteira Sul, Campus Erechim, e-mail: andre.radunz@uffs.edu.br.

Daiani Brandler (iD

Doutoranda em Agronomia pela Universidade Tecnológica Federal do Paraná (UTFPR), Campou Pato Branco, e-mail: daianibrandler@hotmail.com.

Mestrando no Programa de Pós-Graduação em Ciência e Tecnologia Ambiental, da UFFS, Campus Erechim; e-mail: leonardobrunetto@outlook.com.

Antônio Marcos Loureiro da Silva (D)

Mestrando do Programa de Pós-Graduação em Ciência e Tecnologia Ambiental, da UFFS, Campus Erechim, e-mail: antoniomarcoslsr@gmail.com.

Ignacio Aspiazú (D)

Engenheiro Agrônomo, Doutor em Fitotecnia, professor de Plantas Daninhas e Grandes Culturas da Universidade Estadual de Montes Claros; e-mail: aspiazu@gmail.com.

\section{Gismael Francisco Perin}

Engenheiro Agrônomo, Doutor em Engenharia Agrícola, professor de Engenharia Rural da Universidade Federal da Fronteira Sul, Campus Erechim, e-mail: gismaelperin@gmail.com.

\section{RESUMO}

As plantas daninhas Digitaria ciliaris (milhã) e Ipomoea indivisa (corda-de-viola) destacam-se por ocasionarem elevados prejuízos à cultura do milho. Objetivou-se com o trabalho avaliar a interação competitiva relativa entre híbridos de milho na presença de milhã e corda-de-viola, por meio de experimentos em série substitutiva. Os experimentos foram instalados em delineamento experimental de blocos casualizados, com quatro repetições. Primeiramente, tanto para os híbridos de milho (Agroeste - AS 1551 PRO 2, Morgan - MG 300 PW, Nidera - NS 92 PRO e Syngenta - Velox TL) quanto para as plantas daninhas (milhã e corda-de-viola) determinou-se a densidade de plantas em que a produção final se tornou constante (20 plantas vaso $^{-1}$ ou 463 plantas $\mathrm{m}^{-2}$ ). Posteriormente foram instalados oito experimentos para avaliar a habilidade competitiva dos híbridos de milho com as plantas daninhas, ambos conduzidos em série de substituição, nas diferentes combinações das espécies, variando-se as proporções relativas (100:0, 75:25, 50:50, 25:75 e 0:100\%) de plantas vaso-1 (20:0; 15:5; 10:10; 5:15 e 0:20). $A$ análise da competitividade das espécies foi efetuada por meio de diagramas aplicados a 
experimentos substitutivos e também pelos índices de competitividade relativa. Aos 50 dias após a emergência das espécies efetuou-se a aferição da área foliar e da massa seca da parte aérea das plantas. Os híbridos de milho e as plantas daninhas foram afetados negativamente, sendo a competição interespecífica a mais prejudicial para as espécies. A cultura apresentou os maiores índices de competitividade, de crescimento, de dominância e de agressividade. Ao se comparar as espécies entre si, o milho foi mais competitivo do que as plantas daninhas.

Palavras-chave: Digitaria ciliaris; Ipomoea indivisa; Zea mays.

\title{
Competition between corn hybrids with weeds
}

\begin{abstract}
The weeds Digitaria ciliaris (crabgrass) and Ipomoea indivisa (morning glory) stand out for causing many losses in corn. The objective of this work was to evaluate the relative competitive interaction between corn hybrids in the presence of crabgrass and morning glory through replacement series experiments, which were installed in randomized blocks, with four replications. First, for both corn hybrids (Agroeste - AS 1551 PRO 2, Morgan - MG 300 PW, Nidera - NS 92 PRO and Syngenta - Velox TL) and for weeds (crabgrass and morning glory), the density of plants in which the final production became constant was determined (20 plants pot ${ }^{-}$ 1 or 463 plants $m^{-2}$ ). Subsequently, eight experiments were installed to evaluate the competitive ability of corn hybrids with weeds, both conducted in replacement series, in different combinations of species, varying the relative proportions (100:0, 75:25, 50:50, 25:75 and $0: 100 \%)$ plants pot 1 (20:0; 15:5; 10:10; 5:15 and 0:20). The analysis of the species competitiveness was carried out by diagrams applied to experiments with replacement series and also by the relative competitiveness indexes. At 50 days after the emergence of the species, leaf area and dry mass of the shoots of the plants were measured. Corn hybrids and weeds were negatively affected, with interspecific competition being the most damaging to species. The crop showed the highest values for competitiveness rates, growth, dominance and aggressiveness. When comparing species to each other, corn was more competitive than weeds.
\end{abstract}

Keywords: Digitaria ciliaris; Ipomoea indivisa; Zea mays.

\section{Competencia entre híbridos de maíz y malezas}

\section{RESUMEN}

Las malas hierbas Digitaria ciliaris (pasto) e Ipomoea indivisa (bejuco) se destacan por causar muchas pérdidas en el cultivo de maíz. El objetivo de este trabajo fue evaluar la interacción competitiva relativa entre híbridos de maíz en presencia de $D$. ciliaris e $I$. indivisa mediante experimentos en una serie de reemplazo. Los experimentos se instalaron en un diseño de bloques al azar con cuatro repeticiones. En primer lugar, tanto para los híbridos de maíz (Agroeste - AS 1551 PRO 2, Morgan - MG 300 PW, Nidera - NS 92 PRO y Syngenta - Velox TL) como para las malezas (D. ciliaris e l. indivisa) se determinó la densidad de plantas en las que la producción final se ha vuelto constante (20 plantas por maceta 0463 plantas $\mathrm{m}^{-2}$ ). Posteriormente, se instalaron ocho experimentos para evaluar la capacidad competitiva de híbridos de maíz con malezas, ambos realizados en una serie de reemplazo, en diferentes combinaciones de especies, variando las proporciones relativas (100: 0, 75:25, 50: 50, $25: 75$ y 0: 100\%) de plantas por maceta (20: 0; 15: 5; 10:10; 5:15 y 0:20). El análisis de la competitividad de las especies se realizó mediante diagramas aplicados a experimentos de reemplazo y también mediante los índices de competitividad relativa. A los 50 días de la emergencia de la especie se midió el área foliar y la masa seca de la parte aérea de las plantas. Los híbridos de maíz y las malezas fueron afectados negativamente, siendo la competencia interespecífica la más dañina para las especies. La cultura tuvo los niveles más altos de competitividad, mayor crecimiento, mayor dominio y mayor agresividad. Al comparar especies entre sí, el maíz resultó más competitivo que las malas hierbas.

Palabras clave: Digitaria ciliaris; Ipomoea indivisa; Zea mays. 


\section{Introdução}

O milho é utilizado na alimentação animal e humana ou mesmo para a fabricação de etanol, sendo o terceiro cereal mais cultivado no mundo, apresentando grande importância social e econômica. O Brasil é o terceiro maior produtor mundial, com mais de 100 milhões de toneladas, sendo superado apenas pela China e Estados unidos (CONAB, 2020; USDA, 2020).

A produtividade de uma lavoura de milho está relacionada com o manejo adotado durante o crescimento e desenvolvimento da cultura. Desse modo, um dos principais desafios encontrados pelos produtores são as plantas daninhas que competem com o milho pelos recursos do meio, como água, nutrientes e luz, além de liberarem substâncias alelopáticas que afetam negativamente a cultura. As plantas daninhas ocasionam aumento dos custos de produção, são hospedeiras de insetos e doenças, diminuem qualidade de grãos e principalmente trazem reduções significativas na produtividade, podendo ser superiores a 80\% (VARGAS et al., 2006; GALON et al., 2018; BASSO et al., 2018).

A porcentagem das perdas e o grau de competição está relacionado com a espécie daninha presente na lavoura, sua densidade, cultivar utilizada, período que está competindo com a cultura e as práticas de manejo adotadas (WANDSCHEER et al., 2014; FRANDOLOSO et al., 2019). Uma das maneiras de quantificar as perdas ocasionadas pela competição entre espécies de plantas é avaliando a habilidade competitiva das culturas com as plantas daninhas, verificando assim qual a melhor maneira de possibilitar que as culturas expressem o seu maior potencial produtivo (BIANCHI et al., 2006; FLECK et al., 2008; AGOSTINETTO et al., 2013).

A avaliação das interações competitivas entre espécies de plantas daninhas com as plantas cultivadas demanda delineamentos experimentais e métodos de análise adequados, sendo que um dos métodos mais 
utilizados é o convencional em série de substituição, que permite ao pesquisador entender se a competição é inter ou intraespecífica. Os experimentos conduzidos pelo método substitutivo demonstram que a cultura é mais competitiva do que as plantas daninhas, geralmente quando há recursos adequados (FLECK et al., 2008; AGOSTINETTO et al., 2013; WANDSCHEER et al., 2013). A competitividade superior de uma espécie em relação a outra indica que terá maior capacidade de assimilar recursos e portanto, terá maior potencial de crescer e se desenvolver quando em comunidade (AGOSTINETTO et al., 2013).

Muitas são as plantas daninhas que infestam a cultura do milho, destacando como as principais, o papuã (Urochloa plantaginea), caruru (Amaranthus spp.), leiteiro (Euphorbia heterophylla), guanxuma (Sida rhombifolia), buvas (Conyza bonariensis, C. canadensis e C. sumatrensis), capim-pé-de-galinha (Eleusine indica), grama-seda (Cynodon dactylon), tiriricas (Cyperus spp.), carrapicho-de-carneiro (Acanthospermum hispidum), falsa-serralha (Emilia sonchifolia), beldroega (Portulacca oleracea), milhã ou capim-colchão (Digitaria spp.), corda-de-viola (Ipomoea spp.), dentre outras. Todas essas espécies apresentam potencial competitivo com o milho, gerando redução da produtiva e da qualidade de grãos caso nem um método de controle seja adotado (LORENZI, 2014; RODRIGUES et al., 2019; MELO et al., 2019).

O gênero Ipomoea, da família Convolvulaceae, possui diversas espécies no Brasil como, I. grandifolia, I. hederifolia, I. nil, I. purpurea, I. quamoclit, I. triloba e I. indivisa, conhecidas popularmente como cordas-deviola, com grande potencial de infestação de diversas culturas como canade-açúcar, milho, cereais de inverno, soja, feijão, entre outras (LORENZI, 2014). As espécies de Ipomoea podem emergir em camadas de palha de até $15 \mathrm{t} \mathrm{ha}^{-1}$ e conforme o sistema radicular dessas plantas vai crescendo aumenta-se a competição com a cultura, diminuindo assim a absorção de luz, causando prejuízos à fotossíntese e consequentemente a produtividade (AZANIA et al., 2002). Além disso, muitas dessas espécies interferem na 
colheita de grãos e elevam os custos de manejo, pois apresentam tolerância a herbicidas (AGOSTINETO et al., 2016; BARROSO et al., 2019).

O gênero Digitaria abrange várias espécies, como $D$. ciliares, $D$. sanguinalis e D. horizontalis dentre outras. D. ciliaris, conhecida popularmente por capim-colchão ou milhã, infesta áreas cultivadas com diferentes culturas. A diferenciação das espécies de Digitaria é complexa, difícil a campo, devido às semelhanças morfológicas que apresentam (LORENZI, 2014; FONTANA et al., 2016). A milhã pertence a família Poaceae, caracteriza-se como uma planta anual, herbácea, ereta, de 30 a $80 \mathrm{~cm}$ de altura, entouceirada, de colmos finos com enraizamento nos nós, folhas de 6-12 cm de comprimento, com bainhas de coloração verde-escura ou pigmentação púrpura e inflorescência terminal do tipo panícula e reprodução principalmente por sementes (LORENZI, 2014; FONTANA et al., 2016).

O conhecimento da habilidade competitiva do milho em relação às plantas daninhas permite determinar o estresse ocasionado tanto à cultura como ao competidor, e desse modo, desenvolver práticas de manejo eficientes para aumentar a produtividade e a lucratividade do produtor rural. Há diferenciação na habilidade competitiva dos híbridos de milho em competição com densidades de plantas de milhã e de corda-de-viola quando as mesmas vivem em associações na comunidade.

Diante disso objetivou-se com o trabalho avaliar a interação competitiva relativa entre híbridos de milho na presença de milhã e corda-deviola, por meio de experimentos em série substitutiva.

\section{Material e Métodos}

Foram instalados 14 experimentos em casa de vegetação da Universidade Federal da Fronteira Sul (UFFS), Campus Erechim, RS, entre os meses de novembro de 2015 a fevereiro de 2016. As unidades experimentais foram constituídas por vasos plásticos com capacidade para 8 $\mathrm{dm}^{3}$, preenchidos com solo oriundo de área agrícola, caracterizado como Latossolo Vermelho Aluminoférrico húmico (EMBRAPA, 2013). A correção 
da fertilidade do solo foi realizada conforme as recomendações técnicas à cultura do milho e tendo por base a análise físico-química (ROLAS, 2016). As características químicas e físicas do solo foram: $\mathrm{pH}$ em água de 4,8; $\mathrm{MO}$ $=3,5 \% ; \mathrm{P}=4,0 \mathrm{mg} \mathrm{dm}^{-3} ; \mathrm{K}=117,0 \mathrm{mg} \mathrm{dm}^{-3} ; \mathrm{Al}^{3+}=0,6 \mathrm{cmolc} \mathrm{dm}^{-3} ; \mathrm{Ca}^{2+}=$ 4,7 cmolc $\mathrm{dm}^{-3} ; \mathrm{Mg}^{2+}=1,8$ cmolc $\mathrm{dm}^{-3} ; \mathrm{CTC}(\mathrm{t})=7,4$ cmolc $\mathrm{dm}^{-3}$; CTC $(\mathrm{TpH}=7,0)=16,5 \mathrm{cmolc} \mathrm{dm}^{-3} ; \mathrm{H}+\mathrm{Al}=9,7 \mathrm{cmolc} \mathrm{dm}^{-3} ; \mathrm{SB}=6,8 \mathrm{cmolc} \mathrm{dm}^{-}$ 3. $\mathrm{V}=41 \%$ e Argila $=60 \%$.

O delineamento experimental adotado, em todos os experimentos, foi o de blocos casualizados, com quatro repetições. Os competidores testados incluíram os híbridos de milho Agroeste (AS 1551 PRO 2), Morgan (MG 300 PW), Nidera (NS 92 PRO), Syngenta (Velox TL) que competiram com as plantas daninhas milhã (Digitaria ciliaris) e corda-de-viola (Ipomoea indivisa). As principais características dos híbridos de milho testados nos ensaios estão dispostas na Tabela 1.

Tabela 1. Características genéticas dos híbridos utilizados no estudo. UFFS, Campus Erechim/RS, 2014/15.

\begin{tabular}{lccc}
\hline Empresa & Pedigree & Genótipo & Ciclo e biotecnologia \\
\hline Agroeste & AS 1551 PRO2 & Híbrido Simples & Superprecoce e biotecnologia VT PRO2 \\
\hline Morgan & MG 300 PW & Híbrido Simples & Superprecoce e biotecnologia PowerCore \\
\hline Nidera & NS 92 PRO & Híbrido Simples & Precoce e biotecnologia VT PRO \\
\hline Syngenta & Velox TL & Híbrido Simples & Precoce e biotecnologia TL \\
\hline
\end{tabular}

Em caráter preliminar, tanto para os híbridos de milho quanto para a milhã e a corda-de-viola, em monocultivo efetuou-se seis experimentos com objetivo de estimar a densidade de plantas em que a produção final de massa seca atingisse rendimento constante (BIANCHI et al., 2006). Para isso foram utilizadas as densidades de 1, 2, 4, 8, 16, 24, 32, 40, 48, 56 e 64 plantas vaso $^{-1}$ (equivalentes a 25, 49, 98, 196, 392, 587, 784, 980, 1.176, 1.372 e 1.568 plantas $\mathrm{m}^{-2}$ ). Aos 50 dias após a emergência das espécies, coletou-se a parte aérea das plantas de milho e/ou das plantas daninhas para determinar a massa seca da parte aérea (MS), sendo essa quantificada pela pesagem, após serem secas em estufa de circulação forçada de ar a temperatura de $65 \pm 5^{\circ} \mathrm{C}$ até atingir massa constante. Através dos valores médios de MS das espécies obteve-se produção constante com densidade 
de 20 plantas vaso $^{-1}$, para todos os híbridos de milho e/ou as plantas daninhas o que equivaleu a 463 plantas $\mathrm{m}^{-2}$ (dados não apresentados).

Outros oito experimentos foram instalados para avaliar a habilidade competitiva dos híbridos de milho Agroeste (AS 1551 PRO 2), Morgan (MG $300 \mathrm{PW}$ ), Nidera (NS $92 \mathrm{PRO}$ ) e Syngenta (Velox TL) com plantas de milhã e corda-de-viola, ambos conduzidos em série de substituição, nas diferentes combinações dos híbridos e das plantas daninhas, variando-se as proporções relativas de plantas vaso ${ }^{-1}: 100: 0,75: 25,50: 50,25: 75$ e 0:100 o que equivale a 20:0, 15:5, 10:10, 5:15 e 0:20 plantas vaso $^{-1}$ das espécies, mantendo-se constante a densidade total de plantas (20 plantas vaso ${ }^{-1}$ ). Para estabelecer as densidades desejadas em cada tratamento e obter uniformidade das plântulas, as sementes foram previamente semeadas em bandejas, sendo posteriormente transplantadas para os vasos.

Aos 50 dias após a emergência das espécies efetuou-se a aferição da área foliar (AF) e da massa seca (MS). Para os híbridos de milho em competição com a corda-de-viola foi avaliado somente a massa seca da parte aérea das espécies em função de que essa planta daninha enrolou-se às plantas de milho e com isso dificultou a separação das mesmas sem cortar em pequenos pedaços o que impediu de determinar a AF. A determinação da $A F$, nas espécies que foi aferido, foi efetuada com um medidor portátil de área foliar modelo $\mathrm{Cl}-203$ BioScence, quantificando-se a variável em todas as plantas em cada tratamento. Após a quantificação da $\mathrm{AF}$, a parte aérea das plantas foi acondicionada em sacos de papel kraft e submetida a secagem em estufa de circulação forçada de ar, a temperatura de $60 \pm 5 \stackrel{\circ}{ }$, até se obter massa constante.

Os dados foram analisados por meio do método da análise gráfica da variação ou produtividade relativa (COUSENS, 1991; BIANCHI et al., 2006). O referido procedimento, também conhecido como método convencional para experimentos substitutivos, consiste na construção de um diagrama tendo por base as produtividades ou variações relativas (PR) e total (PRT). Quando o resultado da PR for uma linha reta, significa que as habilidades das espécies são equivalentes. Se a PR resultar em linha 
côncava, houve prejuízo no crescimento de uma ou de ambas as espécies. Ao contrário, se a PR resultar em linha convexa, há benefício no crescimento de uma ou de ambas as espécies. Quando a PRT for igual à unidade 1 (linha reta), ocorre competição pelos mesmos recursos; se ela for superior a 1 (linha convexa), a competição é evitada. Caso a PRT for menor que 1 (linha côncava), ocorre prejuízo mútuo ao crescimento (COUSENS, 1991).

Foram calculados ainda os índices de competitividade relativa $(C R)$, coeficiente de agrupamento relativo $(K)$ e agressividade $(A)$ das espécies. $O$ $\mathrm{CR}$ representa o crescimento comparativo dos híbridos de milho $(X)$ em relação aos competidores milhã e corda-de-viola $(\mathrm{Y}) ; \mathrm{K}$ indica a dominância relativa de uma espécie sobre a outra; e $A$ aponta qual das espécies é mais agressiva. Assim, os índices CR, K e A indicam qual espécie se manifesta mais competitiva e sua interpretação conjunta indica com maior segurança a competitividade das espécies (COUSENS, 1991). Os híbridos de milho $X$ são mais competitivos que os competidores milhã e corda-de-viola $Y$ quando $\mathrm{CR}>1, \mathrm{~K}_{\mathrm{x}}>\mathrm{K}_{\mathrm{y}}$ e $\mathrm{A}>0$; por outro lado, os competidores $\mathrm{Y}$ são mais competitivos que os híbridos de milho $X$ quando $C R<1, K_{x}<K_{y}$ e $A<0$ (HOFFMAN; BUHLER, 2002). Para calcular esses índices foram usadas as proporções 50:50 das espécies envolvidas no experimento (milho versus milhã e/ou corda-de-viola), ou seja, as populações de 10:10 plantas vaso ${ }^{-1}$, utilizando-se as equações: $C R=P R x / P R y ; K_{x}=P R x /(1-P R x) ; K_{y}=P R y /(1-$ $\left.P R_{y}\right) ; A=P R_{x}-P R_{y}$, de acordo com Cousens; O'Neill (1993).

O procedimento de análise estatística da produtividade ou variação relativa incluiu o cálculo das diferenças para os valores de PR (DPR) obtidos nas proporções 25,50 e $75 \%$ em relação aos valores pertencentes à reta hipotética nas respectivas proporções, quais sejam, 0,25, 0,50 e 0,75 para PR (BIANCHI et al., 2006; AGOSTINETTO et al., 2013). Utilizou-se o teste $t$ para testar as diferenças relativas aos índices DPR, PRT, CR, $\mathrm{K}$ e A (HOFFMAN; BUHLER, 2002). Considerou-se como hipótese nula, para testar as diferenças de DPR e A, que as médias fossem iguais a zero $\left(\mathrm{H}_{0}=\right.$ $0)$; para PRT e CR, que as médias fossem iguais a um $\left(H_{\circ}=1\right)$; e para $K$, que as médias das diferenças entre $\mathrm{K}_{\mathrm{x}}$ e $\mathrm{K}_{\mathrm{y}}$ fossem iguais a zero $\left[\mathrm{H}_{0}=\left(\mathrm{K}_{\mathrm{x}}-\right.\right.$ 
$\left.\mathrm{K}_{\mathrm{y}}\right)=0$ ]. O critério para se considerar as curvas de PR e PRT diferentes das retas hipotéticas foi que, no mínimo em duas proporções, ocorressem diferenças significativas pelo teste " $\mathrm{t}$ " (BIANCHI et al., 2006; AGOSTINETTO et al., 2013). Do mesmo modo, considerou-se, para os índices $\mathrm{CR}, \mathrm{K}$ e A, a existência de diferenças em competitividade quando, no mínimo em dois deles, houvesse diferença significativa pelo teste $\mathrm{T}$.

Os resultados obtidos para AF e MS tanto do milho quanto dos competidores, expressos em valores médios por tratamento, foram submetidos à análise de variância pelo teste $\mathrm{F}$ e quando esse foi significativo compararam-se as médias dos tratamentos pelo teste de Dunnett, considerando-se as monoculturas como testemunhas nessas comparações. Em todas as análises estatísticas efetuadas adotou-se $p \leq 0,05$.

\section{Resultados e discussão}

Os resultados gráficos demonstram nas combinações de plantas dos híbridos de milho (Agroeste - AS 1551 PRO 2, Morgan - MG 300 PW, Nidera - NS 92 PRO e Syngenta - Velox TL), com as plantas daninhas (milhã e corda-de-viola) que ocorreu semelhança na competição entre a cultura e os competidores, havendo diferenças significativas para as variáveis AF e MS nas proporções de plantas testadas. Com relação à PRT, ocorreu diferenças significativas entre os valores esperados e estimados, de modo geral, para todas as variáveis estudadas, tendo estas apresentadas valores médios menores que 1 para AF e MS em todas as combinações das proporções de plantas da cultura e do competidor (Figuras 1, 2 e 3; Tabela 2). Esses resultados da PRT de linhas côncavas e valores inferiores a 1, permitem inferir que ocorreu competição entre o milho, a milhã e a corda-de-viola pelos mesmos recursos disponíveis no meio. Segundo Rubin et al., (2014) quando a PRT < 1 há um antagonismo mútuo entre as espécies que estão competindo pelos recursos do ambiente. Fato esse também observado por Frandoloso et al., (2019) ao estudarem diferentes híbridos de milho em competição com o papuã. 
A presença de linhas côncavas em todas as simulações indicou que ocorreu competição pelos mesmos recursos do ambiente, havendo prejuízo mútuo para o crescimento tanto da cultura quanto do competidor (RUBIN et al., 2014). Essas perdas são observadas mesmo nas menores proporções da espécie daninha, o que indica que essa pode causar danos a cultura mesmo em baixa densidade, como já observado na cultura do milho em convivência com o papuã (FRANDOLOSO et al., 2019) e/ou de soja na presença de picão-preto, leiteiro (FORTE et al., 2017) e de nabo (BIANCHI et al., 2006).
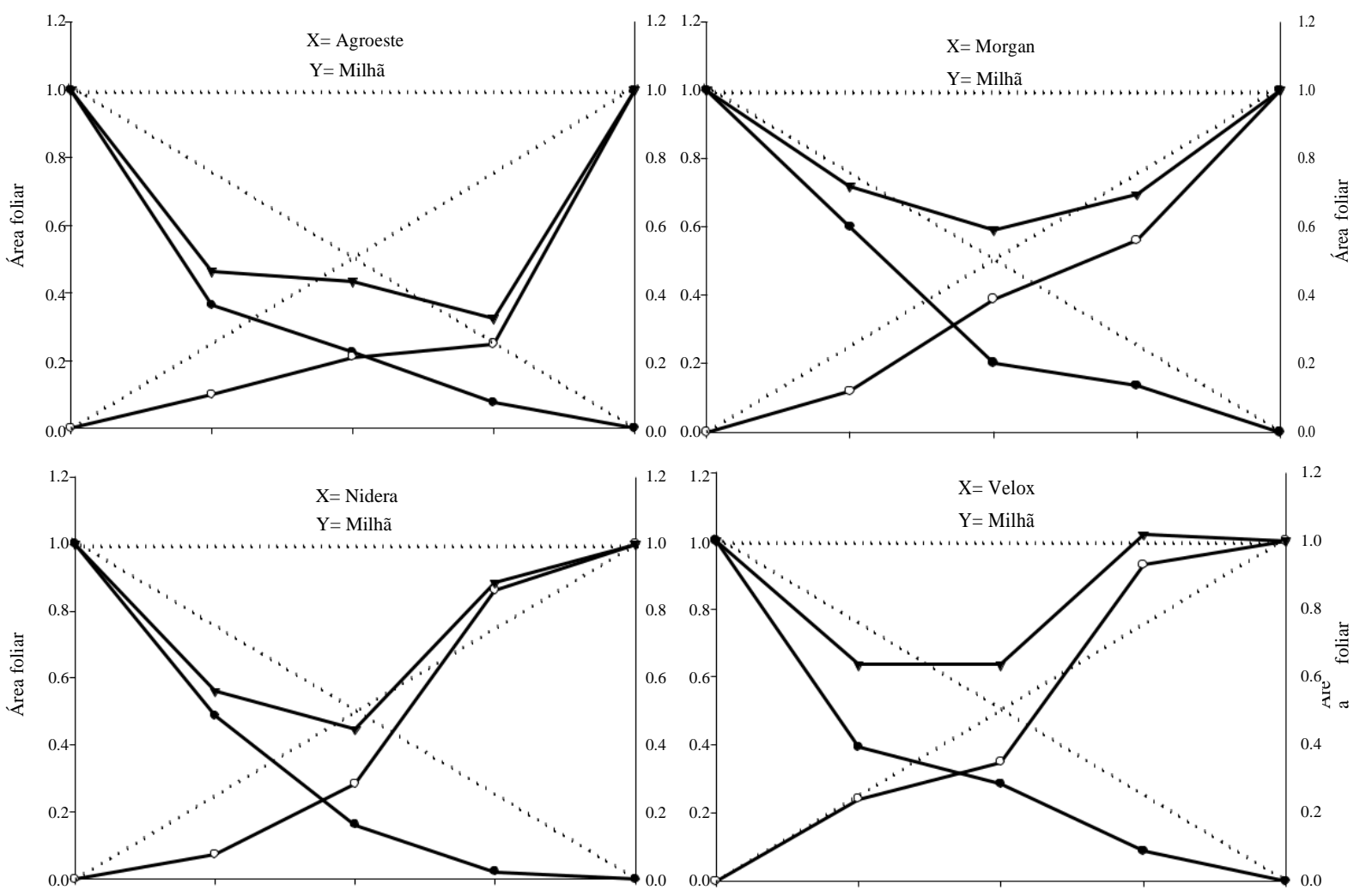

Figura 1. Produtividade relativa (PR) para área foliar relativa das plantas de milho $(\bullet)$, milhã $\left({ }^{\prime}\right)$, e produtividade relativa total (PRT) da comunidade $(\mathbf{\Delta})$ em função da proporção de plantas (milho: milhã). Linhas tracejadas representam os valores esperados, na ausência de competição, e linhas sólidas os valores observados quando as espécies competiram em diferentes proporções de plantas. UFFS, Campus Erechim/RS, 2014/15.

De maneira geral, ocorreu a presença de linhas côncavas em todas as simulações para as variáveis AF e MS indicando assim que houve competição pelos mesmos recursos do ambiente, havendo prejuízo mútuo para o crescimento, tanto da cultura quanto dos competidores milhã e cordade-viola (Figuras 1, 2 e 3). Em todas as simulações avaliadas das PR e PRT as espécies diferiram entre si para as variáveis em estudo (Figuras 1, 2 e 3; 
Tabela 2). Desse modo houve competição entre as espécies pelos mesmos recursos disponíveis no meio, com prejuízo mútuo ao crescimento e desenvolvimento das mesmas. Rubin et al., (2014) também observaram PRT < 1 ocorrendo assim antagonismo mútuo entre as espécies quando em competição pelos mesmos recursos do ambiente. Em condições semelhantes, Wandscheer et al., (2014), ao avaliarem o milho competindo com capim-sudão, também denotaram que a PRT apresentou linha côncava para as comparações.
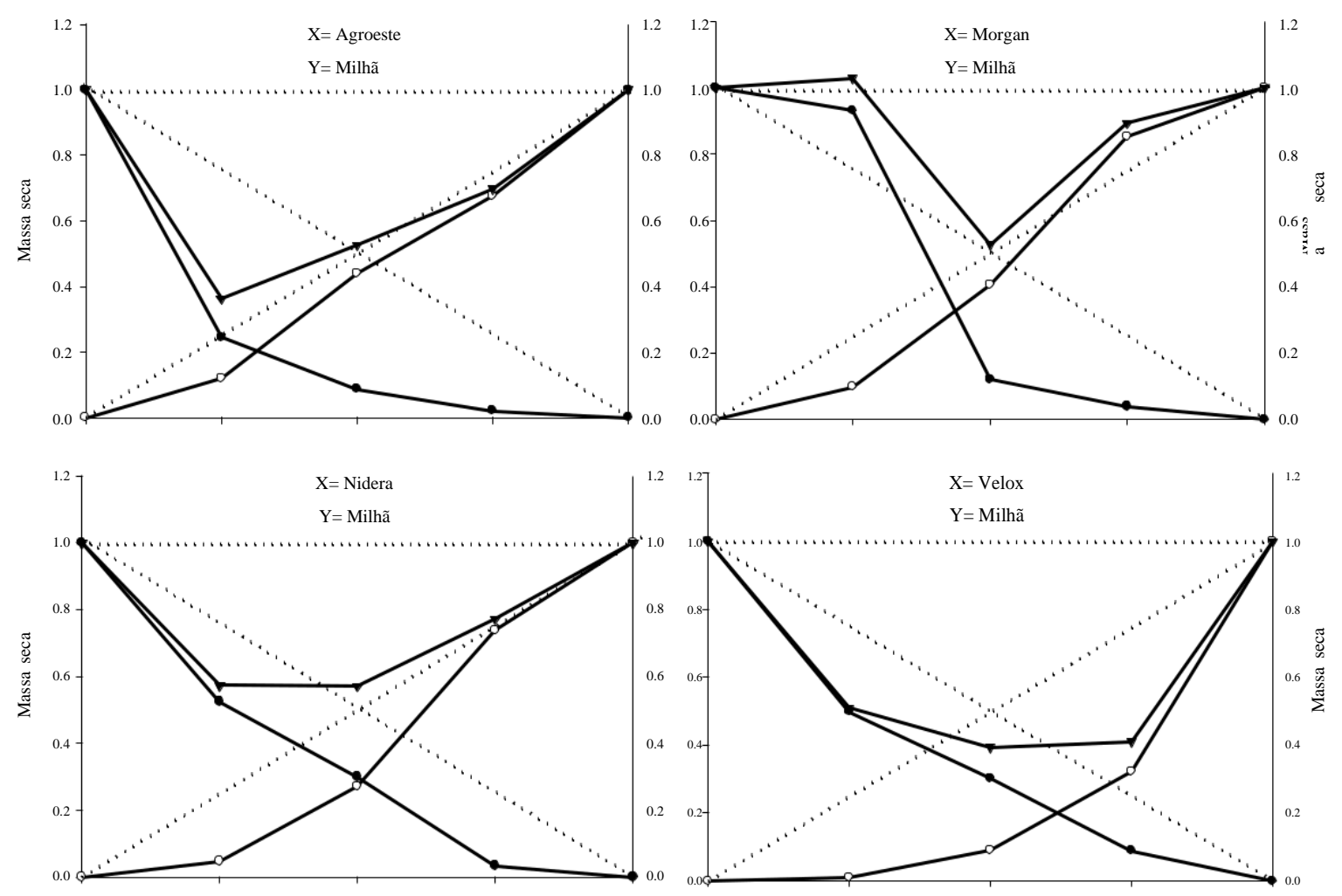

Figura 2. Produtividade relativa $(\mathrm{PR})$ para massa seca relativa das plantas de milho $(\bullet)$, milhã $\left({ }^{O}\right)$, e produtividade relativa total $(\mathrm{PRT})$ da comunidade $(\boldsymbol{\Delta})$ em função da proporção de plantas (milho: milhã). Linhas tracejadas representam os valores esperados, na ausência de competição, e linhas sólidas os valores observados quando as espécies competiram em diferentes proporções de plantas. UFFS, Campus Erechim/RS, 2014/15.

Os competidores apresentaram comportamento distindo em relação ao crescimento relative das espécies, tendo a milhã maior e a corda-de-viola menor crescimentos relativos ao competirem com os híbridos de milho Agroeste, Morgan, Nidera e Syngenta e a corda-de-viola o menor, porém contribuíram muito pouco para a PRT (Figuras 1, 2 e 3; Tabela 2). O crescimento inicial mais rápido de uma espécie, quando em competição com 
outra em uma comunidade vegetal pode ocasionar vantagem competitiva para a mesma, sendo o que provavelmente ocorreu com a milhã e a cordade-viola no presente estudo. Galon; Agostinetto (2009) constaram que as cultivares de arroz irrigado que apresentaram crescimento inicial mais rápido demonstram maior habilidade competitiva em relação as cultivares de arroz com crescimento mais lento, quando em competição com o capim-arroz.

Ressalta-se ainda que, em experimentos substitutivos, existe pouca evidência de haver mudanças qualitativas devido ao aumento da densidade, ou seja, a dominância de uma espécie sobre a outra raramente muda com a alteração da população (COUSENS; O'NEILL, 1993). Corroboram aos resultados observados no presente estudo os constatados por Agostinetto et al. (2008); Fleck et al. (2008) e Frandoloso et al. (2019). No entanto, resultados contraditórios foram verificados por Agostinetto et al., (2013) ao avaliarem o comportamento diferenciado na competição de arroz e soja com milhã, sendo as culturas nesse caso mais competitivas do que a planta daninha, ocorrendo diferenças entre as espécies na competição.

Os resultados demonstram que ocorreu diferenças das PRs dos híbridos de milho ao competirem com a milhã e a corda-de-viola, em relação às respectivas retas hipotéticas, em pelo menos duas proporções de plantas nas associações (Figuras 1, 2 e 3; Tabela 2). De acordo com Bianchi et al. (2006) para haver significância pelo menos duas proporções de plantas devem diferir, e foram verificadas diferenças entre as retas estudadas e esperadas para AF e MS em todas as proporções de plantas avaliadas. Observou-se no presente trabalho que nem o milho e as plantas daninhas apresentaram maior habilidade competitiva, ocorrendo prejuízos ao crescimento das espécies na comunidade, em especial o milho, pois as plantas daninhas normalmente em áreas agrícolas aparecem em densidades superiores às das plantas cultivadas e na maioria das situações são consideradas como mais competitivas no uso dos recursos disponíveis no meio (BIANCHI et al., 2006). 

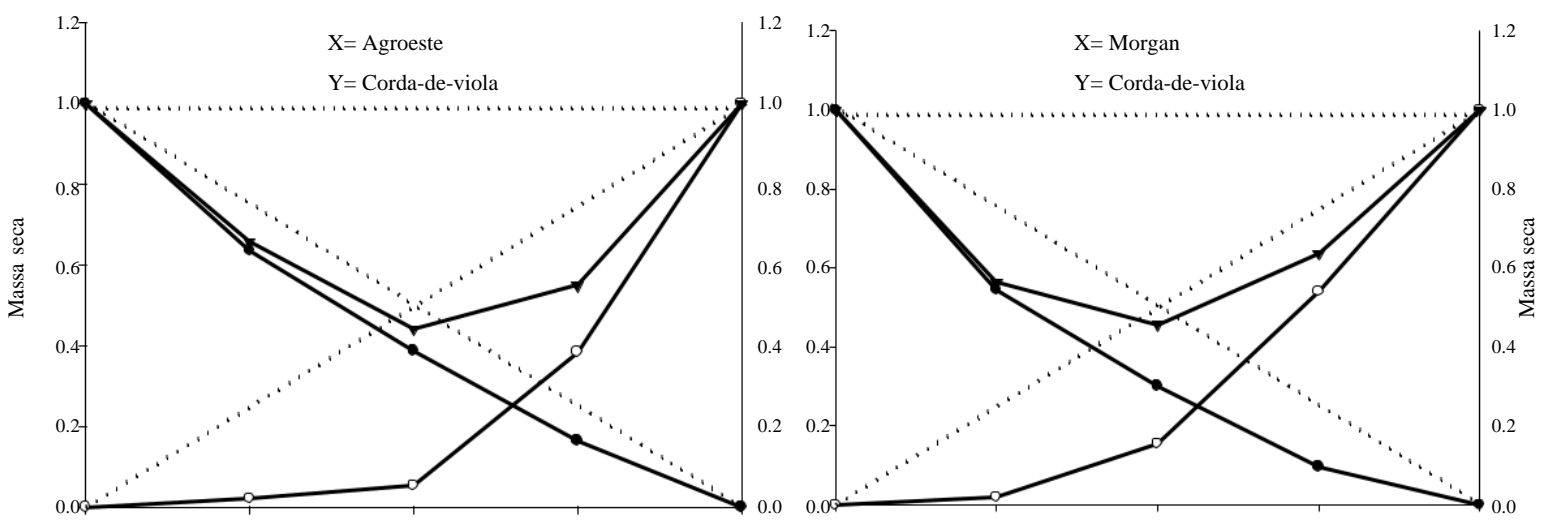

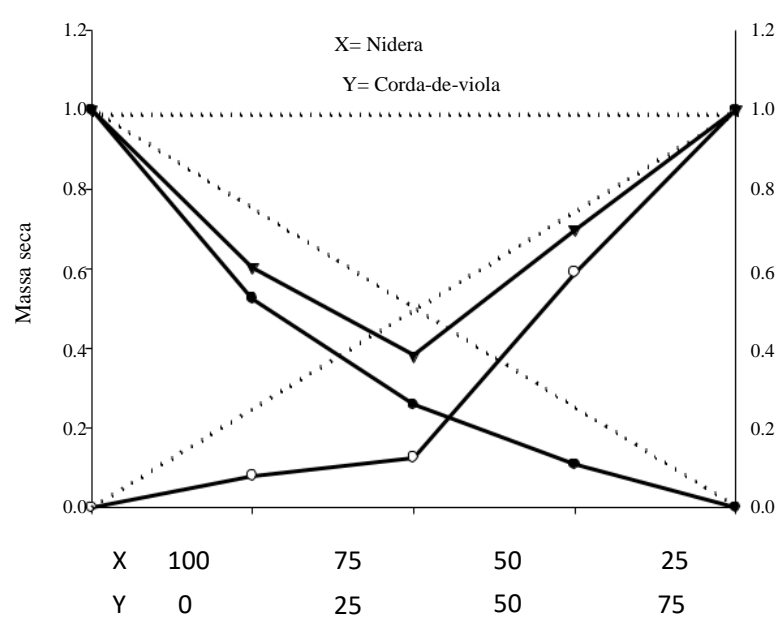

Proporção copetitiva entre cultura: planta daninha (\%)

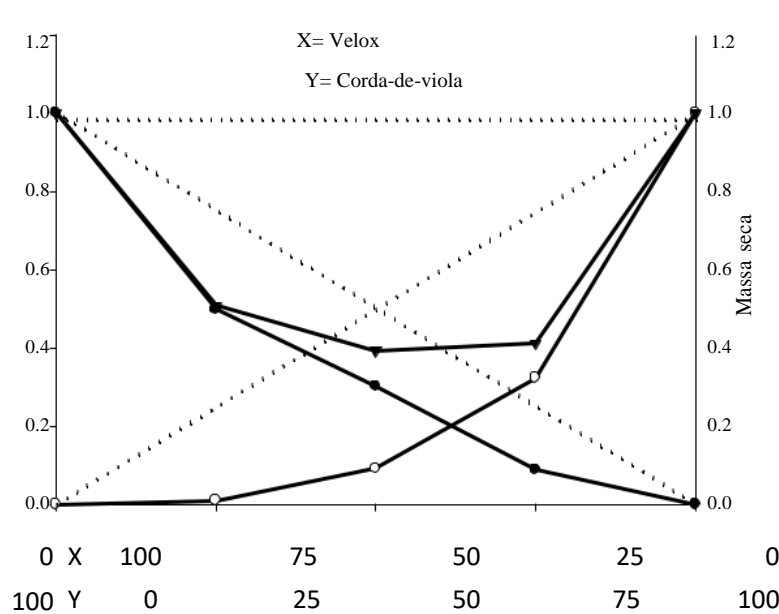

Proporção copetitiva entre cultura: planta daninha (\%)

Figura 3. Produtividade relativa $(P R)$ para massa seca relativa das plantas de milho $(\bullet)$, corda-de-viola ( $)$, e produtividade relativa total (PRT) da comunidade $(\boldsymbol{\Lambda})$ em função da proporção de plantas (milho: corda-de-viola). Linhas tracejadas representam os valores esperados, na ausência de competição, e linhas sólidas os valores observados quando as espécies competiram em diferentes proporções de plantas. UFFS, Campus Erechim/RS, 2014/15.

As variáveis morfológicas AF e MS dos híbridos de milho Agroeste (AS 1551 PRO 2), Morgan (MG 300 PW), Nidera (NS 92 PRO) e Syngenta (Velox TL) foram reduzidas quando competiram com a milhã e a corda-deviola em todas as proporções de plantas na associação (Tabelas 3 e 4). Quanto mais elevada a proporção dos competidores na associação com os híbridos de milho, maiores foram os danos às variáveis da cultura. Nas plantas daninhas (milhã e corda-de-viola) observou-se redução na AF e na MS, quando em igual ou menor proporção de plantas, comparativamente aos híbridos de milho. 
Tabela 2. Diferenças relativas para as variáveis área foliar e massa seca da parte aérea de híbridos de milho (Agroeste - AS 1551 PRO 2, Morgan - MG 300 PW, Nidera - VT PRO Yeld Gard NS 92 PRO e Velox TL) ou de plantas daninhas (milhã - Digitaria ciliaris e corda-de-viola - Ipomoea indivisa), aos 50 dias após a emergência das espécies. UFFS, Campus Erechim/RS, 2014/15.

\begin{tabular}{|c|c|c|c|}
\hline \multirow{3}{*}{ Variáveis } & \multicolumn{3}{|c|}{ Proporções de plantas associadas (milho: competidor) } \\
\hline & $75: 25$ & $50: 50$ & $25: 75$ \\
\hline & \multicolumn{3}{|c|}{ Área foliar do milho $x$ milhã } \\
\hline Nidera & $-0,26( \pm 0,01)^{\star}$ & $-0,34( \pm 0,001)^{\star}$ & $-0,23( \pm 0,001)^{*}$ \\
\hline Milhã & $-0,18( \pm 0,001)^{*}$ & $-0,22( \pm 0,001)^{*}$ & $0,11( \pm 0,02)^{*}$ \\
\hline Total & $0,56( \pm 0,01)^{*}$ & $0,45( \pm 0,001)^{*}$ & $0,88( \pm 0,02)^{*}$ \\
\hline Morgan & $-0,15( \pm 0,01)^{*}$ & $-0,30( \pm 0,01)^{*}$ & $-0,11( \pm 0,01)^{\star}$ \\
\hline Milhã & $-0,13( \pm 0,001)^{*}$ & $-0,11( \pm 0,01)^{*}$ & $-0,19( \pm 0,09)$ \\
\hline Total & $0,72( \pm 0,01)^{*}$ & $0,59( \pm 0,02)^{*}$ & $0,70( \pm 0,09)$ \\
\hline Velox & $-0,36( \pm 0,01)^{*}$ & $-0,21( \pm 0,02)^{\star}$ & $-0,16( \pm 0,03)^{*}$ \\
\hline Milhã & $-0,01( \pm 0,01)^{*}$ & $-0,15( \pm 0,02)^{*}$ & $0,18( \pm 0,02)^{*}$ \\
\hline Total & $0,64( \pm 0,001)^{*}$ & $0,64( \pm 0,01)^{*}$ & $1,02( \pm 0,05)$ \\
\hline Agroeste & $-0,39( \pm 0,03)^{\star}$ & $-0,28( \pm 0,01)^{*}$ & $-0,17( \pm 0,001)^{*}$ \\
\hline Milhã & $-0,15( \pm 0,001)^{*}$ & $-0,29( \pm 0,01)^{*}$ & $-0,50( \pm 0,001)^{*}$ \\
\hline \multirow[t]{2}{*}{ Total } & $0,46( \pm 0,03)^{*}$ & $0,43( \pm 0,01)^{*}$ & $0,32( \pm 0,001)^{*}$ \\
\hline & \multicolumn{3}{|c|}{ Massa seca do milho $x$ milhã } \\
\hline Nidera & $-0,22( \pm 0,02)^{*}$ & $-0,20( \pm 0,01)^{\star}$ & $-0,22( \pm 0,001)^{*}$ \\
\hline Milhã & $-0,20( \pm 0,001)^{*}$ & $-0,23( \pm 0,01)^{*}$ & $-0,01( \pm 0,01)$ \\
\hline Total & $0,57( \pm 0,03)^{*}$ & $0,57\left(( \pm 0,01)^{*}\right.$ & $0,77( \pm 0,01)^{*}$ \\
\hline Morgan & $0,18( \pm 0,07)$ & $-0,38( \pm 0,01)^{*}$ & $-0,21( \pm 0,001)^{*}$ \\
\hline Milhã & $-0,15( \pm 0,01)^{*}$ & $-0,09( \pm 0,01)^{*}$ & $0,10( \pm 0,03)$ \\
\hline Total & $1,03( \pm 0,06)$ & $0,53( \pm 0,001)^{*}$ & $0,89( \pm 0,03)^{*}$ \\
\hline Velox & $-0,54( \pm 0,03)^{*}$ & $-0,21( \pm 0,001)^{\star}$ & $-0,22( \pm 0,001)^{\star}$ \\
\hline Milhã & $-0,21( \pm 0,001)^{*}$ & $-0,41( \pm 0,01)^{\star}$ & $-0,36( \pm 0,03)^{\star}$ \\
\hline Total & $0,26( \pm 0,02)^{*}$ & $0,37( \pm 0,01)^{*}$ & $0,42( \pm 0,002)^{*}$ \\
\hline Agroeste & $-0,51( \pm 0,01)^{\star}$ & $-0,41( \pm 0,001)^{\star}$ & $-0,23( \pm 0,001)^{*}$ \\
\hline Milhã & $-0,13( \pm 0,001)^{*}$ & $-0,06( \pm 0,03)$ & $-0,07( \pm 0,001)^{*}$ \\
\hline \multirow[t]{2}{*}{ Total } & $0,36( \pm 0,01)^{*}$ & $0,53( \pm 0,03)^{*}$ & $0,70( \pm 0,001)^{*}$ \\
\hline & \multicolumn{3}{|c|}{ Massa seca do milho $x$ corda-de-viola } \\
\hline Nidera & $-0,23( \pm 0,03)^{\star}$ & $-0,24( \pm 0,001)^{*}$ & $-0,14( \pm 0,001)^{*}$ \\
\hline Corde-de-viola & $-0,17( \pm 0,01)^{*}$ & $-0,38( \pm 0,01)^{\star}$ & $-0,16( \pm 0,03)^{\star}$ \\
\hline Total & $0,60( \pm 0,02)^{*}$ & $0,38( \pm 0,01)^{*}$ & $0,70( \pm 0,03)^{*}$ \\
\hline Morgan & $-0,21( \pm 0,04)^{*}$ & $-0,20( \pm 0,01)^{*}$ & $-0,15( \pm 0,001)^{*}$ \\
\hline Corda-de-viola & $-0,23( \pm 0,001)^{*}$ & $-0,35( \pm 0,01)^{*}$ & $-0,20( \pm 0,03)^{\star}$ \\
\hline Total & $0,56( \pm 0,03)^{*}$ & $0,46( \pm 0,01)^{*}$ & $0,64( \pm 0,03)^{*}$ \\
\hline Velox & $-0,25( \pm 0,03)^{\star}$ & $-0,20( \pm 0,01)^{*}$ & $-0,16( \pm 0,01)^{\star}$ \\
\hline Corda-de-viola & $-0,24( \pm 0,001)^{*}$ & $-0,41( \pm 0,02)^{*}$ & $-0,43( \pm 0,02)^{*}$ \\
\hline Total & $0,51( \pm 0,03)^{*}$ & $0,39( \pm 0,02) *$ & $0,41( \pm 0,02)^{*}$ \\
\hline Agroeste & $-0,11( \pm 0,02)^{*}$ & $-0,11( \pm 0,02)^{\star}$ & $-0,09( \pm 0,001)^{*}$ \\
\hline Corda-de-viola & $-0,23( \pm 0,001)^{*}$ & $-0,45( \pm 0,01)^{*}$ & $-0,36( \pm 0,001)^{*}$ \\
\hline Total & $0,66( \pm 0.02)^{*}$ & $0.44( \pm 0.02)^{*}$ & $0.55( \pm 0.001)^{*}$ \\
\hline
\end{tabular}

* Diferença significativa pelo teste "T" $(p \leq 0,05)$. Valores entre parênteses representam o erro padrão da média. 
Tabela 3. Diferenças entre plantas associadas ou não de híbridos de milho (Nidera - VT PRO Yeld Gard NS 92 PRO, Morgan - MG 300 PW, Agroeste AS 1551 PRO 2 e Velox TL) e de milhã (Digitaria ciliaris) para as variáveis área foliar e massa seca da parte aérea, aos 50 dias após a emergência das plantas. UFFS, Campus Erechim/RS, 2014/15.

\begin{tabular}{|c|c|c|c|c|}
\hline \multirow{3}{*}{$\begin{array}{l}\text { Proporção } \\
\text { Milho: milhã } \\
\text { Milhã: milho }\end{array}$} & \multicolumn{2}{|c|}{ Área foliar } & \multicolumn{2}{|c|}{ Massa seca } \\
\hline & Milho & Milhã & Milho & Milhã \\
\hline & \multicolumn{2}{|c|}{ Nidera vs milhã } & & \\
\hline $100: 0$ e $100: 0(T)$ & 1683,00 & $868,52^{*}$ & 73,86 & 110,64 \\
\hline $75: 25$ e $75: 25$ & $1093,35^{\star}$ & 755,18 & $54,71^{*}$ & 108,83 \\
\hline $50: 50$ e $50: 50$ & $546,83^{*}$ & $429,29^{*}$ & $44,31^{*}$ & $59,97^{*}$ \\
\hline $25: 75$ e $25: 75$ & $150,06^{*}$ & $223,89^{*}$ & $10,10^{*}$ & $21,46^{*}$ \\
\hline$C V(\%)$ & 2,03 & 5,12 & 7,72 & 3,66 \\
\hline \multicolumn{5}{|c|}{ Morgan vs milhã } \\
\hline $100: 0(\mathrm{~T})$ & 954,88 & 665,36 & 76,56 & 111,07 \\
\hline $75: 25$ & $764,25^{\star}$ & $496,94^{*}$ & $60,85^{*}$ & $97,59^{*}$ \\
\hline $50: 50$ & $386,82^{*}$ & 518,33 & $14,71^{*}$ & $79,27^{*}$ \\
\hline $25: 75$ & $516,79^{*}$ & $316,78^{*}$ & $9,64^{*}$ & $38,41^{*}$ \\
\hline$C V(\%)$ & 5,86 & 14,02 & 12,80 & 6,04 \\
\hline \multicolumn{5}{|c|}{ Agroeste vs milhã } \\
\hline $100: 0(T)$ & 822,44 & 1126,73 & 113,91 & 90,50 \\
\hline $75: 25$ & $398,91^{*}$ & $374,50^{\star}$ & $37,01^{*}$ & 81,73 \\
\hline $50: 50$ & $367,80^{*}$ & $474,20^{*}$ & $19,75^{\star}$ & $79,56^{*}$ \\
\hline $25: 75$ & $248,17^{*}$ & $449,51^{*}$ & $9,31^{*}$ & $43,30^{*}$ \\
\hline$C V(\%)$ & 6,75 & 9,96 & 8,19 & 6,01 \\
\hline \multicolumn{5}{|c|}{ Velox vs milhã } \\
\hline $100: 0(T)$ & 1255,61 & 560,11 & $112,71^{*}$ & 192,50 \\
\hline $75: 25$ & $659,89^{*}$ & $693,48^{*}$ & 32,24 & $99,92^{*}$ \\
\hline $50: 50$ & $718,79^{*}$ & $391,74^{*}$ & $64,52^{*}$ & $32,91^{*}$ \\
\hline $25: 75$ & $590,32^{*}$ & $541,54^{*}$ & $14,53^{*}$ & $32,62^{*}$ \\
\hline$C V(\%)$ & 8,01 & 7,06 & 14,77 & 10,34 \\
\hline
\end{tabular}

* Média difere da testemunha (T) pelo teste de Dunnett $(p \leq 0,05)$.

Estudos demonstram que pode ocorrer prejuízo ao crescimento das culturas e das plantas daninhas quando essas estiverem em competição numa determinada comunidade (AGOSTINETTO et al., 2013; GALON et al., 2018; FRANDOLOSO et al., 2019). Os menores valores de acúmulo de AF e MS demostra a elevada competição interespecífica, em que as espécies disputam os mesmos recursos do meio, conforme constatado por 
Frandoloso et al. (2019) ao avaliarem a interferência entre papuã e híbridos de milho. No presente estudo a cultura encontrava-se bem distribuída, o que eleva a habilidade competitiva da mesma, enquanto a distribuição em linhas, geralmente utilizada a campo, incrementa os danos causados pela comunidade infestante (DUSABUMUREMYI et al., 2014).

Tabela 4. Diferenças entre plantas associadas ou não de híbridos de milho (Nidera - VT PRO Yeld Gard NS 92 PRO, Morgan - MG 300 PW, Agroeste AS 1551 PRO 2 e Velox TL) e de corda-de-viola (Ipomoea indivisa) para a variavel massa seca da parte aérea, aos 50 dias após a emergência das plantas. UFFS, Campus Erechim/RS, 2014/15.

\begin{tabular}{|c|c|c|}
\hline \multirow{3}{*}{$\begin{array}{l}\text { Proporção } \\
\text { Milho: corda-de-viola } \\
\text { Corda-de-viola: milho }\end{array}$} & \multicolumn{2}{|c|}{ Massa seca } \\
\hline & Milho & Corda-de-viola \\
\hline & \multicolumn{2}{|l|}{ Nidera vs corda-de-viola } \\
\hline $100: 0(\mathrm{~T})$ & 115,20 & 31,84 \\
\hline $75: 25$ & $80,63^{*}$ & $25,10^{*}$ \\
\hline $50: 50$ & $59,40^{*}$ & $7,94^{*}$ \\
\hline $25: 75$ & $49,70^{*}$ & $10,04^{*}$ \\
\hline$C V(\%)$ & 6,19 & 13,17 \\
\hline \multicolumn{3}{|c|}{ Morgan vs corda-de-viola } \\
\hline $100: 0(T)$ & 113,99 & 32,95 \\
\hline $75: 25$ & $82,76^{*}$ & $23,73^{*}$ \\
\hline $50: 50$ & $68,83^{*}$ & $10,17^{*}$ \\
\hline $25: 75$ & $44,21^{*}$ & $2,52^{*}$ \\
\hline$C V(\%)$ & 7,21 & 13,23 \\
\hline \multicolumn{3}{|c|}{ Agroeste vs corda-de-viola } \\
\hline $100: 0(T)$ & 102,26 & 23,71 \\
\hline $75: 25$ & $86,85^{*}$ & $12,18^{*}$ \\
\hline $50: 50$ & $79,31^{*}$ & $2,54^{*}$ \\
\hline $25: 75$ & $67,34^{*}$ & $2,01^{*}$ \\
\hline$C V(\%)$ & 5,25 & 7,11 \\
\hline \multicolumn{3}{|c|}{ Velox vs corda-de-viola } \\
\hline $100: 0(\mathrm{~T})$ & 107,09 & 46,86 \\
\hline $75: 25$ & $71,08^{*}$ & $20,14^{*}$ \\
\hline $50: 50$ & $64,68^{*}$ & $8,59^{*}$ \\
\hline $25: 75$ & $38,04^{*}$ & $2,04^{*}$ \\
\hline$C V(\%)$ & 10,93 & 17,56 \\
\hline
\end{tabular}

Os resultados demonstram que as variáveis AF e MS apresentaram as maiores médias por planta da cultura ou mesmo dos competidores quando estas se apresentavam em densidades menores na associação em todas as combinações (Tabela 3 e 4). Desse modo constata-se que a competição interespecífica é mais prejudicial para ambas as espécies envolvidas do que a competição intraespecífica. Frandaloso et al. (2019) também observaram que o efeito da competição interespecíficas foi mais prejudicial do que a intraespefica ao trabalharem com milho na presença do 
papuã. Zanine; Santos, (2004) descrevem que a redução no crescimento de espécies, envolvidas em combinações intra ou interespecíficas, resulta da competição espacial entre grupos de plantas que ocupam o mesmo espaço. Outros trabalhos envolvendo diferentes espécies de plantas em competição também denotaram efeitos similares aos constatados no presente estudo, como trigo na presença de nabo (TAVARES et al., 2019), arroz em competição com capim-arroz (GALON; AGOSTINETTO, 2009), arroz e soja $x$ milhã (AGOSTINETTO et al., 2013), trigo x nabo (COSTA; RIZZARDI, 2015) e soja $x$ plantas daninhas (FORTE et al., 2017).

A competição afeta quantiqualitativamente a produção, pois modifica a eficiência de aproveitamento dos recursos do ambiente, como água, luz, $\mathrm{CO}_{2}$ e nutrientes, estabelecendo-se entre a cultura e as plantas de outras espécies existentes no local (BIANCHI et al., 2006). Essa competição ocorre também entre indivíduos de uma mesma espécie ou entre biótipos predominantes na área, conforme constatado por Ferreira et al., (2008), os quais verificaram que biótipos de azevém resistentes ao glyphosate possuem menor capacidade competitiva do que os suscetíveis. Destaca-se ainda que em uma comunidade de plantas há beneficio na competição pelos recursos para aquelas que se estabelecem primeiro, pelas características intrínsecas de cada cultivar ou híbrido quanto à habilidade competitiva (sistema radicular, estatura, índice de área foliar, produção de massa seca, velocidade de crescimento, número de afilhos, entre outras), pelo melhor aproveitamento ou necessidade dos recursos por uma determinada espécie dentro de um nicho ecológico.

O híbrido de milho X (Agroeste - AS 1551 PRO 2, Morgan - MG 300 PW, Nidera - NS 92 PRO e Syngenta - Velox TL) é mais competitivo que a milhã e/ou corda-de-viola $\mathrm{Y}$, quando comparados pelos coeficientes desenvolvidos por Hoffman; Buhler (2002), CR > 1, $K_{x}>K_{y}$ e A > 0. Assim, adotou-se como critério para comprovar superioridade competitiva, a ocorrência de diferença significativa em pelo menos dois desses índices (BIANCHI et al., 2006). Observou-se em geral que os híbridos de milho apresentaram o menor crescimento, para as variáveis AF e MS quando em 
competição com a milhã, conforme indicado pelos índices CR (menor que 1), $K$ da cultura menor que o da planta daninha e A (negativo), exceto para a AF do Agroeste que não houve significância e a MS do Nidera e Velox onde a cultura demonstrou maior competitividade do que a milhã em todos os índices ( $\mathrm{CR}, \mathrm{K}$ e A). Ao se levar em conta os índices de competitividade (CR,

$\mathrm{K}$ e A) para a corda-de-viola em competição com o milho, observou-se que todos os híbridos foram mais competitivos com $\mathrm{CR}>1, \mathrm{~K}$ da cultura $>\mathrm{K}$ da corda-de-viola e A positivo (Tabela 5). Resultados similares ao do presente estudo foram obtidos por Frandoloso et al., (2019) ao trabalharem com híbridos de milho e papuã.

De maneira geral verificou-se diferenças entre os híbridos de milho em competição com a milhã ou corda-de-viola, o que demonstra que ambos não se equivalem em termos competitivos pelos recursos do ambiente, destacando-se que a cultura foi menos competitiva na presença da milhã e mais quando infestada pela corda-de-viola (Tabela 5). Conforme já comentado que a milhã apresenta crescimento inicial mais rapido que a corda-de-viola, tem-se ainda a diferença de metabolismo fotossintético, onde a milhã é uma planta C4 e a corda-de-viola uma planta C3. Plantas C4 são caracterizadas por demonstrarem melhor capacidade para aproveitarem os recursos disponíveis no meio e, desse modo, normalmente, se mostram mais competitivas do que plantas C3 (SILVA et al., 2014).

Pode-se ainda relatar que a provável causa do milho ter apresentado maior índice de competitividade do que a corda-de-viola está relacionado com a altura de plantas, tornando a cultura mais apta e eficiente na busca por luz, ocorrendo assim sombreamento a planta daninha (ALMEIDA; MUNDSTOCK, 2001). Já os maiores indices de competitividade observados pela milhã em relação ao milho, pode estar relacionado ao fato de ambos pertencerem a mesma família (Poaceae) e, como as plantas daninhas apresentam maior agressividade levam vantagem na competição. A competição diferenciada das espécies daninhas sobre a cultura pode ser explicada pelas características das espécies infestantes. $O$ alto grau de interferência da milhã sobre o milho está mais relacionado a densidade e a 
distribuição com que ocorre nas lavouras do que sua capacidade individual de competir com as culturas (TANVEER et al., 2015).

Tabela 5. Índices de competitividade entre híbridos de milho (Agroeste - AS 1551 PRO 2, Morgan -MG 300 PW, Nidera - VT PRO Yeld Gard NS 92 PRO e Velox TL), milhã (Digitaria ciliaris) e corda-de-viola (Ipomoea indivisa), expressos por competitividade relativa (CR), coeficientes de agrupamentos relativos $(K)$ e de agressividade $(A)$, obtidos em experimentos conduzidos em séries substitutivas, aos 50 dias após a emergência das espécies. UFFS, Campus Erechim/RS, 2014/15.

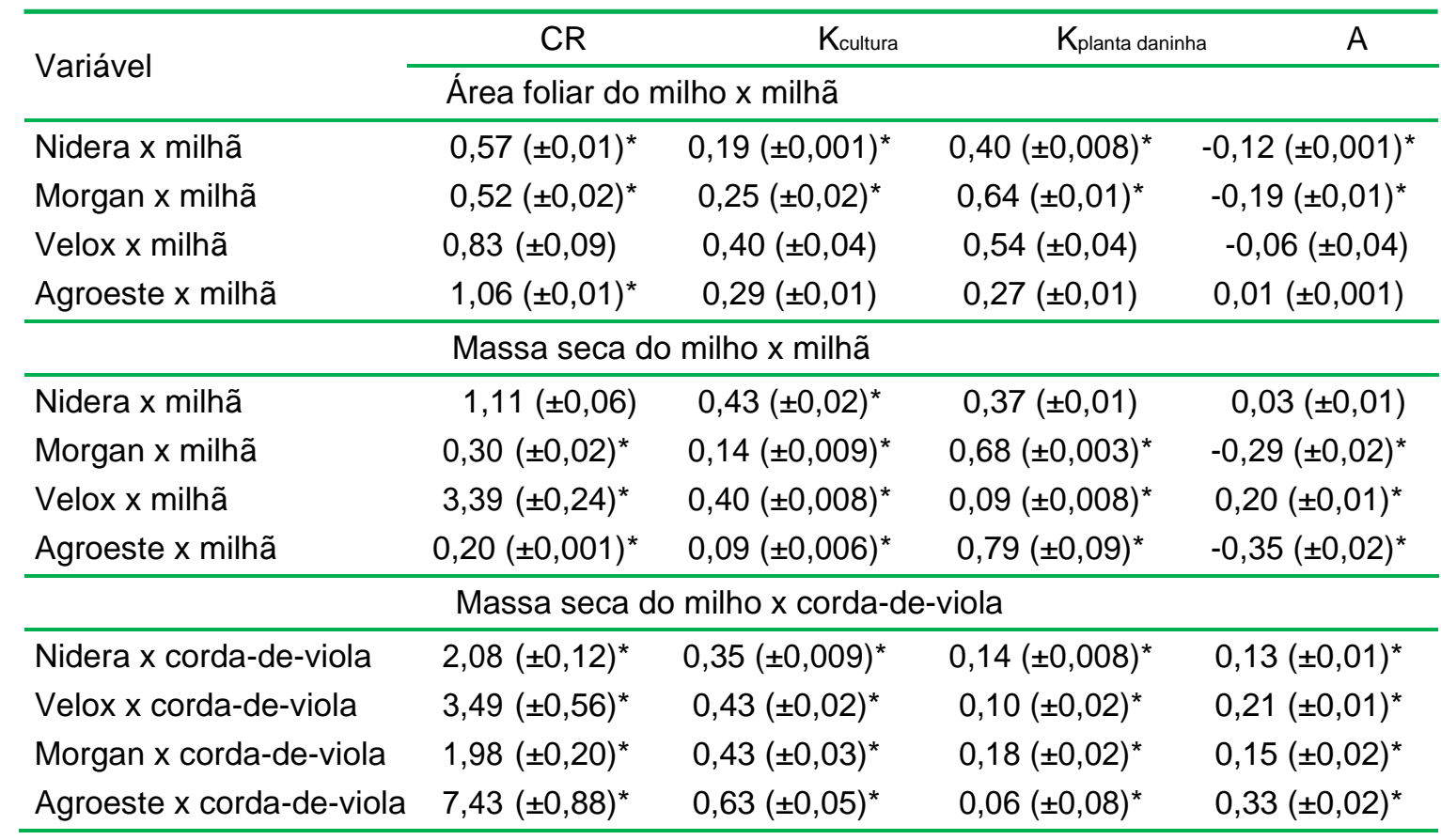

Em geral quando uma espécie for mais competitiva que a outra essa terá maior capacidade de assimilação dos recursos que estão disponíveis no meio, vindo a incrementar o potencial de desenvolvimento e crescimento, e consequentemente gerando danos ao competidor, pois menores quantidades de recursos ficaram disponíveis (AGOSTINETTO et al., 2013). Quando ocorre competição por luz, compromete o incremento de área foliar e massa seca, pois as plantas estão muito próximas e ocorre interferência no crescimento e na formação das folhas (WU et al., 2012).

O alto grau de interferência da milhã sobre o milho se caracteriza pela planta daninha ser mais adaptada as condições de alta temperatura e luminosidade, pela emissão de perfilhos e alta capacidade competitiva com as culturas em virtude de sua rápida taxa de crescimento (FONTANA et al., 
2016). Outra característica que pode estar relacionada com a elevada capacidade de utilização dos recursos do meio pela milhã, indisponibilizando-os assim para o milho. Apesar de ambas as espécies possuírem metabolismo $\mathrm{C} 4$, o milho apresenta desenvolvimento inicial lento, o que o torna suscetível a competição das plantas daninhas, principalmente durante o seu crescimento inicial (SILVA et al., 2014). Corrobora com os resultados do presente estudo os encontrados por Wandscheer et al., (2014) que também constataram que o milho foi menos competitivo que o capimsudão. De maneira contrária é observado que o sorgo sacarino foi mais competitivo que o leiteiro e menos ao ser infestado pelo papuã (GALON et al., 2018).

Utilizando os três índices para definir competitividade, foi observado que os híbridos de milho foram mais competitivos que o papuã (FRANDOLOSO et al., 2019), que o sorgo cultivado foi mais competitivo que o Sorghum halepense (HOFFMAN; BUHLER, 2002) e que o leiteiro (GALON et al., 2018), que cultivares de soja foram mais competitivas que plantas daninhas (FORTE et al., 2017) e que arroz-vermelho apresentou maior agressividade que o arroz irrigado (FLECK et al., 2008). De acordo com Vilá et al. (2004) quando se semeia as culturas em associação com plantas daninhas, com variação na proporção de plantas, normalmente as culturas apresentam vantagem quanto a produtividade relativa, demonstrando assim que a competição intraespecífica excede a interespecífica.

Ao se analisar conjuntamente os gráficos relacionados com as variáveis relativas e suas significâncias em relação aos valores equivalentes (Figuras 1; 2 e 3; Tabela 2), as variáveis morfológicas (Tabelas 3 e 4) e os índices de competitividade (Tabela 5) no geral observou-se existir efeitos de competição da milhã ou da corda-de-viola sobre os híbridos de milho (Agroeste - AS 1551 PRO 2, Morgan - MG 300 PW, Nidera - NS 92 PRO e Syngenta - Velox TL) demonstrando que essas espécies daninhas apresentam elevada habilidade competitiva em relação a cultura. Corrobora com presente trabalho os resultados encontrados por Frandoloso et al., (2019) ao denotarem que o papuã também apresentou maior 
competitividade do que diferentes híbridos de milho. Por disputarem basicamente os mesmos recursos do meio, o milho, a milhã ou corda-deviola competem por recursos similares na comunidade onde estão convivendo. Desse modo as diferenças em termos de competitividade, entre o milho e as plantas daninhas, pode estar relacionado ao fato dessas espécies apresentarem demandas de nutrientes, luz e água semelhantes entre si. Pesquisas tem relatado que as espécies pertencendo a famílias botânicas, com características morfofisiológicas diferentes; sorgo sacarino $\mathrm{x}$ leiteiro (GALON et al., 2018), nabo $x$ soja (BIANCHI et al., 2006), milhã $x$ soja (AGOSTINETTO et al., 2013), ou semelhantes milho em competição com o papuã (FRANDOLOSO et al., 2019) e milho $x$ capim-sudão (WANDSCHEER et al., 2014), sorgo $x$ sorgo de alepo (HOFFMAN; BUHLER, 2002) e trigo $x$ azevém (RIGOLI et al., 2008) apresentaram similaridades na demanda por recursos do meio.

Conhecer a dinâmica e a competitividade entre plantas, em especial o milho e milhã ou corda-de-viola, torna-se importante para a tomada de decisão de controlar as plantas daninhas em determinada densidade, de modo que estas não ocasionem interferência negativa sobre a cultura. $A$ milhã (Digitaria spp.) tem capacidade de produzir um grande número de sementes, facilitando sua dispersão, bem como a capacidade competitiva e a fecundidade das espécies em um ambiente competitivo (FONTANA et al., 2016). A D. sanguinalis infesta as lavouras vindo a reduzir a produtividade das culturas, mesmo em baixa densidade (PEREIRA et al., 2011). Wang et al., (2018) relatam que a $D$. sanguinalis tem como fator crítico a temperatura e luz, pois afetam a germinação das sementes, porém essa se adapta a uma ampla faixa de níveis de $\mathrm{pH}$, o que indica que pode se adaptar a diversos ambientes e condições do solo, fator esse que explica sua ampla distribuição em todo o mundo.

A corda-de-viola além de competir com as culturas por água, luz e nutrientes ainda devido ao enrolamento que faz nas plantas causa elevados prejuízos as mesmas. Piccinini et al. (2018) observaram que mesmo em 
densidades baixas a Ipomoea sp. afetou os componentes de rendimento da soja.

Desse modo, o entendimento da dinâmica e da habilidade competitiva quando as plantas cultivadas e daninhas estiverem convivendo em mesma comunidade torna-se importante para a escolha de uma determinada tática de manejo ao infestarem as lavouras.

\section{Conclusões}

Ocorre competição entre os híbridos de milho (Agroeste - AS 1551 PRO 2, Morgan - MG 300 PW, Nidera - NS 92 PRO e Syngenta - Velox TL) com a milhã ou com a corda-de-viola, sendo afetados negativamente, independentemente da proporção de plantas, provocando reduções na AF e MS das espécies. A competição interespecífica causa maiores prejuízos a AF e a MS das espécies do que a competição intraespecífica. Ocorre basicamente a competição pelos mesmos recursos do meio entre o milho com as plantas daninhas. Ao se comparar as espécies entre si, o milho foi mais competitivo do que a corda-de-viola e menos que a milhã.

\section{Agradecimentos}

Ao CNPq, à FAPERGS, a UFFS e ao FINEP pelo auxílio financeiro à pesquisa e pelas concessões de bolsas. 


\section{Referências}

AGOSTINETTO, D. et al. Período crítico de competição de plantas daninhas com a cultura do trigo. Planta Daninha, v.26, n.2, p.271-278, 2008. https://doi.org/10.1590/S0100-83582008000200003.

AGOSTINETTO, D. et al. Habilidade competitiva relativa de milhã em convivência com arroz irrigado e soja. Pesquisa Agropecuária Brasileira, v.48, n.10, p.1315-1322, 2013. https://doi.org/10.1590/S0100204X2013001000002.

AGOSTINETO, M.C. et al. Sinergismo de misturas de glyphosate e herbicidas inibidores da PROTOX no controle de corda-de-viola. Revista de Ciências Agroveterinárias, v.15, n.1, p.8-15, 2016. https://doi.org/10.5965/223811711512016008.

ALMEIDA, M.L.de; MUNDSTOCK, C.M. A qualidade da luz afeta o afilhamento em plantas de trigo, quando cultivadas sob competição. Ciência Rural, v.31, n.3, p.401-408, 2001. https://doi.org/10.1590/S010384782001000300006 .

AZANIA, A.A.P.M. et al. Interferência da palha de cana-de-açúcar (Saccharum spp.) na emergência de espécies de plantas daninhas da família convolvulaceae. Planta Daninha, v.20, n.2, p.207-212, 2002. https://doi.org/10.1590/S0100-83582002000200006.

BARROSO A.A.M.; FERREIRA P.S.H.; MARTINS D. Crescimento e desenvolvimento de plantas daninhas do gênero Ipomoea. Planta Daninha, v. 34, 2019. Planta Daninha, v37:e019186421, 2019. https://doi.org/10.1590/S0100-83582019370100034

BASSO, F.J.M. et al. Manejo de plantas daninhas em milho $R^{\circledR}{ }^{\circledR}$ com herbicidas aplicados isoladamente ou associados ao glyphosate. Revista de Ciências Agroveterinárias, v.17, n.2, p.148-157, 2018. https://doi.org/10.5965/223811711722018148 .

BIANCHI, M.A.; FLECK, N.G.; LAMEGO, F.P. Proporção entre plantas de soja e plantas competidoras e as relações de interferência mútua. Ciência Rural, v.36, n.5, p.1380-1387, 2006. https://doi.org/10.1590/S010384782006000500006 .

CONAB - COMPANHIA NACIONAL DE ABASTECIMENTO. Acompanhamento da safra brasileira de grãos. Disponível em: http://www.conab.gov.br. Acesso em: 01 out. 2020.

COSTA, L.O.; RIZZARDI, M.A. Habilidade competitiva de trigo em convivência com biótipos de Raphanus raphanistrum $\mathrm{L}$. resistente $\mathrm{e}$ suscetível aos herbicidas inibidores de ALS. Ciência e Agrotecnologia,

v.39, n.2, p.121-130, 2015. https://doi.org/10.1590/S141370542015000200003 . 
COUSENS, R.; O'NEILL, M. Density dependence of replacement series experiments. Oikos, v.66, n.2, p.347-352, 1993. URL: https://www.jstor.org/stable/3544824.

COUSENS, R. Aspects of the design and interpretation of competition (interference) experiments. Weed Technology, v.5, n.3, p.664-673, 1991. https://doi.org/10.1017/S0890037X00027524.

DUSABUMUREMYI, P.; NIYIBIGIRA, C.; MASHINGAIDZE, A. B. Narrow row planting increases yield and suppresses weeds in common bean (Phaseolus vulgaris L.) in a semi-arid agro-ecology of Nyagatare, Rwanda. Crop
Protection v. 64 ,
n.1,
p. 13-18,
2014. https://doi.org/10.1016/j.cropro.2014.05.021.

EMBRAPA - EMPRESA BRASILEIRA DE PESQUISA AGROPECUÁRIA. Centro Nacional de Pesquisa Agropecuária de Solos (Brasília, DF). Sistema brasileiro de classificação de solos. Brasília: Embrapa Produção de Informação; Brasília, DF: Embrapa Solos, 2013. 154 p.

FERREIRA, E. A. et al. Glyphosate distribution and nutrient accumulation in ryegrass biotypes. Planta Daninha, v.26, n.1, p.165-173, 2008. https://doi.org/10.1590/S0100-83582008000100017.

FLECK, N. G. et al. Relative competitivity among flooded rice cultivars and a red rice biotype. Planta Daninha, v.26, n.1, p.101-111, 2008. https://doi.org/10.1590/S0100-83582008000100011.

FONTANA, L.C. et al. Levantamento de espécies de Digitaria ("milhã") em áreas de cultivo agrícola no Rio Grande do Sul (Brasil). Revista Brasileira de Biociências, v.14, n.1, p.1-8, 2016.

FORTE, C. T. et al. Habilidade competitiva de cultivares de soja transgênica convivendo com plantas daninhas. Revista Brasileira de Ciências
Agrárias,
v.12,
n.2,
p.185-193,
2017.

https://doi.org/10.5039/agraria.v12i2a5444.

FRANDOLOSO, F. et al. Competition of maize hybrids with alexandergrass ('Urochloa plantaginea). Australian Journal of Crop Science, v.13, n.9, p.1447, 2019. https://doi.org/10.21475/ajcs.19.13.09.p1540.

GALON, L. et al. Chemical management of weeds in corn hybrids. Weed

Biology and Management, v.18, n.1, p.26-40, 2018. https://doi.org/doi:10.1111/wbm.12141.

GALON, L.; AGOSTINETTO, D. Comparison of empirical models for predicting yield loss of irrigated rice (Oryza sativa) mixed with Echinochloa spp. Crop Protection, v.28, n.10, p.825-830, 2009. https://doi.org/10.1016/j.cropro.2009.06.005.

HOFFMAN, M. L.; BUHLER, D. D. Utilizing Sorghum as a functional model of crop-weed competition. I. Establishing a competitive hierarchy. Weed 
Science, v.50, n.4, p.466-472, 2002. https://doi.org/10.1614/00431745(2002)050[0473:USAAFM]2.0.CO;2.

LORENZI, H. Manual de identificação e controle de plantas daninhas: plantio direto e convencional. 7. ed. Nova Odessa, 382p., 2014.

MELO T.S.; MAKINO P.A.; CECCON G. Weed diversity in corn with different plant arrangement patterns grown alone and intercropped with palisade grass. Planta Daninha, v37:e019195957, 2019. https://doi.org/10.1590/s0100-83582019370100103.

PEREIRA, M. R. R. et al. Inhibition of the initial development of sunflower, corn and triticale plants by crabgrass. Planta Daninha, v.29, n.2, p.305-310, 2011. https://doi.org/10.1590/S0100-83582011000200008.

PICCININI, F. et al. Interferência de cordas-de-viola na produtividade da soja. Planta Daninha, v.36, e018150988, 2018. http://dx.doi.org/10.1590/s0100-83582018360100063.

RIGOLI, R.P. et al. Habilidade competitiva relativa do trigo (Triticum aestivum) em convivência com azevém (Lolium multiflorum) ou nabo (Raphanus raphanistrum). Planta Daninha, v.26, n.1, p.93-100, 2008. https://doi.org/10.1590/S0100-83582008000100010.

RODRIGUES, L.D.S. et al. Milho tolerante ao glifosato: interação entre herbicidas pós-emergentes e época de controle das plantas daninhas. Revista Brasileira de Milho e Sorgo, v.18, n.2, p. 168-177, 2019. https://doi.org/10.18512/1980-6477/rbms.v18n2p168-177.

ROLAS - Rede oficial de laboratórios de análise de solo e de tecido vegetal. Manual de calagem e adubação para os estados do Rio Grande do Sul e de Santa Catarina. Porto Alegre: Sociedade Brasileira de Ciência do Solo Núcleo Regional Sul: Comissão de Química e Fertilidade do Solo - RS/SC, 2016. 376p.

RUBIN, R.S. et al. Habilidade competitiva relativa de arroz irrigado com arroz-vermelho suscetível ou resistente ao herbicida imazapyr + imazapic. Arquivos do Instituto Biológico, v.81, n.2, p.173-179. 2014. https://doi.org/10.1590/1808-1657001242012.

SILVA, A.F. et al. Manejo de plantas daninhas. In: BORÉM A. et al. (Eds.). Sorgo: do plantio à colheita. Viçosa: UFV, 2014.

TANVEER, A. et al. Yield losses in chickpea with varying densities of dragon spurge (Euphorbia dracunculoides). Weed Science, v.63, n.2, p.522-528, 2015. https://doi.org/10.1614/WS-D-13-00049.1.

TAVARES, L. C. et al. Criteria for decision making and economic threshold level for wild radish in wheat crop. Planta Daninha, v.37, e019178898, 2019. https://doi.org/10.1590/s0100-83582019370100004. 
USDA - UNITED STATES DEPARTMENT OF AGRICULTURE. Production, Supply and Distribution. Online. Disponível em: http://www.usda.gov/wps/portal/usda/usdahome?navid=DATA_STATISTICS. Acesso em: 12 mar. 2020.

VARGAS, L.; PEIXOTO, C. M.; ROMAN, E. S. Manejo de plantas daninhas na cultura do milho. Passo Fundo: EMBRAPA-CNPT, p. 61, 2006.

VILÁ M., WILLIAMSON, M., LONSDALE, M. Competition experiments on alien weeds with crops: Lessons for measuring plant invasion impact?

Biological Invasions, v.6, n.1, p.59-69, 2004. 10.1023/B:BINV.0000010122.77024.8a.

WANDSCHEER, A. C. D. et al. Capacidade competitiva da cultura do milho em relação ao capim-sudão. Revista Brasileira de Milho e Sorgo, v.13, n.2, p.129-141, 2014. http://dx.doi.org/10.18512/1980-6477/rbms.v13n2p129141.

WANG, Y. H. et al. Fatores abióticos que afetam a Germinação e a emergência precoce de plântulas de milhã (Digitaria sanguinalis). Planta Daninha, v.36, e018166895, 2018. http://dx.di.org/10.1590/s010083582018360100068 .

WU, W. et al. Sensitivity analysis of crop growth models to multi-temporal scale solar radiation. Transactions of the Chinese Society of Agricultural Engineering, $\quad$ v. $28, \quad$ n. $3, \quad$ p. 123-128, 2012. https://doi.org/10.3969/j.issn.1002-6819.2012.03.022.

ZANINE, A.M.; SANTOS, E.M. Competition among species of plants - A review. Revista da Faculdade de Zootecnia, Veterinária e Agronomia, v.11, n.1, p.10-30, 2004. 